\section{Blood transfusion in total hip arthroplasty: guidelines to eliminate overtransfusion}

M.M. McSwiney FRCA FFARCSI, D. O'Farrell FRCSI, G.P. Joshi FFarcsi, S.M. McCarroll FFARCSI
This study was designed to evaluate the effect of transfusion guidelines on perioperative blood usage with a view to identifying a protocol for transfusion therapy in our hospital. Eighty consecutive patients with normal haemoglobin concentrations presenting for total hip arthroplasty were studied. The maximum allowable blood loss (MABL) was calculated for each patient using the formula of Kallos et al. Blood loss up to this value was replaced with Haemaccel. When the MABL was reached, a haematocrit (Hct) was performed and blood was given if the Hct was less than 30 in men and 27 in women. Otherwise replacement was with Haemaccel. All postoperative complications, duration of hospital stay, and physiotherapy compliance assessments were recorded. A discharge Hct $>36 \%$ was the criterion for overtransfusion. The results were compared with findings from a retrospective group before the introduction of these guidelines. Analysis of the data demonstrated a reduction in the frequency of transfusion ( $97 \%$ vs $32 \% P<0.05$ ), the volume transfused (2.7 vs 1.3 units $P<0.05$ ), and the incidence of overtransfusion (45\% vs $5 \% P<0.05$ ) between the two groups of patients. There was no difference between the groups in complication rate, duration of hospital stay or physiotherapy scoring. We conclude that the introduction of guidelines for transfusion in total hip arthroplasty patients has produced a marked reduction in blood usage in our hospital without detrimental effect.

Ce travail consiste à évaluer le résultat de l'utilisation de critères transfusionnels créés dans le but de rédiger un protocole régissant l'administration du sang dans notre hôpital. Font l'objet de l'étude, quatre-vingt patients consécutifs programmés pout

\section{Key words}

SURGERY: orthopaedic;

TRANSFUSION: stored blood.

From the Department of Anaesthesia, Cappagh Hospital, Dublin.

Address correspondence to: Dr. M.M. McSwiney, Sir

Humphry Davy Department of Anaesthesia, Bristol Royal

Infirmary, Upper Maudlin Street, Bristol BS2 8HW.

Accepted for publication 31st October, 1992. prothèse totale de la hanche et présentant des concentrations normales d'hémoglobine. La perte sanguine maximale permise est calculée d'après la formule de Kallos et col. Le sang perdu est d'abord remplacé par de l'Hemaccel. Une fois la perte sanguine maximale permise atteinte, on mesure l'hématocrite et on administre du sang si l'hématocrite est inférieur à $30 \%$ chez les hommes et $27 \%$ chez les femmes. Sinon, on remplace par de l'Hemaccel. Les complications postopératoires, la durée du séjour hospitalier et lévaluation de la tolérance à la physiothérapie sont enregistrées. Une mise en congé avec un hématocrite supérieur à $30 \%$ est considérée comme un critère de transfusion excessive. Les résultats sont comparés avec les constatations d'une étude rétrospective réalisée avant lintroduction de ces critères. L'analyse des données montre une diminution dans la fréquence des transfusions $(97 \%$ vs $32 \%, P<$ $0,05)$, du volume transfusé $(2,7$ vs 1,31 unités, $P<0,05)$, et de lincidence de transfusions inutiles (45\% vs 5\%,P<0,05) entre les deux groupes de patients. On n'a pas trouvé de différence entre les groupes en ce qui a trait au pourcentage de complications, à la durée du séjour hospitalier et à la tolérance du patient pour la physiothérapie. Nous concluons que dans notre hôpital l'introduction de critères transfusionnels appliqués aux prothèses totales de la hanche permet une baisse considérable de l'utilisation du sang sans présenter d'effets nuisibles.

Blood is a finite resource with a limited shelf life and is associated with considerable processing costs. Risks of homologous transfusion vary in type and severity. ${ }^{1}$ Morbidity and mortality may result from either an immunologically mediated reaction or a transmitted infection. Although blood is tested for HIV antibodies time may elapse before blood from infected donors tests positive. ${ }^{2,3}$ Transfused blood may disturb the recipient's immune system, affecting the growth of primary and secondary tumours ${ }^{4-6}$ and the development of graft versus host disease. ${ }^{7,8}$ The risk of clerical error or confusion over names can result in patients receiving the wrong blood.

Increasing concern about the risks of homologous transfusion has led to the use of perioperative autologous transfusion. ${ }^{9}$ This technique avoids the problems of in- 
TABLE I Demographic data, preoperative and discharge haemoglobin/haematocrit concentrations, intraoperative and total blood loss for control and study groups

\begin{tabular}{|c|c|c|c|c|c|c|}
\hline & \multicolumn{3}{|l|}{ Control group } & \multicolumn{3}{|l|}{ Study group } \\
\hline & Men & Women & Both & Men & Women & Both \\
\hline$n$ & 63 & 87 & 150 & 36 & 44 & 80 \\
\hline Age (yr) & $64.8 \pm 9.3$ & $67.1 \pm 11.3$ & - & $68.6 \pm 9.1$ & $65.7 \pm 8.6$ & - \\
\hline Weight (kg) & $74.4 \pm 14.1$ & $67.2 \pm 13.2$ & - & $78.9 \pm 12.4$ & $67.5 \pm 10.1$ & - \\
\hline Preoperative $\left(\mathrm{g} \cdot \mathrm{dl}^{-1}\right)$ haemoglobin & $14.2 \pm 1.6$ & $12.9 \pm 1.3$ & - & $14.4 \pm 1.0$ & $13.2 \pm 1.1$ & - \\
\hline Preoperative haematocrit (\%) & $43.6 \pm 3.5$ & $38.6 \pm 4.0$ & - & $43.9 \pm 3.0$ & $39.8 \pm 3.1$ & - \\
\hline Discharge haemoglobin $\left(\mathrm{g} \cdot \mathrm{dl}^{-1}\right)$ & $11.5 \pm 1.5$ & $11.0 \pm 1.5$ & - & $11.2 \pm 1.1$ & $10.6 \pm 0.91$ & - \\
\hline Discharge haematocrit $(\%)$ & $34.5 \pm 3.5$ & $33.1 \pm 1.5$ & - & $33.7 \pm 3.0$ & $31.9 \pm 2.7$ & - \\
\hline Intraoperative blood loss (ml) & $732 \pm 318$ & $794 \pm 332$ & $760 \pm 324$ & $801 \pm 346$ & $765 \pm 343$ & $781 \pm 345$ \\
\hline Total blood loss (ml) & $1520 \pm 460$ & $1390 \pm 465$ & $1440 \pm 520$ & $1522 \pm 472$ & $1413 \pm 473$ & $1462 \pm 476$ \\
\hline
\end{tabular}

TABLE II Hip pathology and anaesthetic technique employed for control and study groups

\begin{tabular}{lll}
\hline Pathology & Control group & Study group \\
\hline Rheumatoid arthritis & $20(13.3 \%)$ & $11(13.8 \%)$ \\
Osteoarthritis & $126(84 \%)$ & $68(85 \%)$ \\
Other & $4(2.7 \%)$ & $1(1.2 \%)$ \\
& & \\
Anaesthetic technique & & \\
Spinal anaesthesia & $137(91.3 \%)$ & $74(92.5 \%)$ \\
General anaesthesia & $12(8 \%)$. & $6(7.5 \%)$ \\
Epidural anaesthesia & $1(0.7 \%)$ & 0 \\
\hline
\end{tabular}

fection or immune disturbance and leaves only the risk of clerical error. However, the logistics are considerable and since the blood is processed in the usual fashion there are no cost savings. Most patients undergoing total hip arthroplasty receive routine perioperative blood transfusion ${ }^{10}$ and, until recently, routine transfusion does not appear to have been questioned.

Blood transfusion was classified by the American Joint Commission on Accreditation of Hospitals as "high volume, high risk and error prone." Utilisation of this resource needs critical review to identify areas of overuse and thus reduce risk to patient and hospital costs. Demands for blood may be reduced by studying blood utilisation (quality assessment) and establishing guidelines for transfusion of elective surgical patients.

The aims of this study were to evaluate transfusion guidelines in patients undergoing elective total hip arthroplasty, to compare transfusion in this group with transfusion in a retrospective control group, and to determine the effect of the guidelines on overtransfusion and perioperative morbidity.

\section{Methods}

Following Ethical Committee approval and informed consent, 80 consecutive patients with normal haemoglobin concentrations (men $>13$, women $>11.5 \mathrm{~g} \cdot \mathrm{dl}^{-1}$ ), presenting for total hip arthroplasty were included. $\mathrm{Pa}$ tients for revision total hip arthroplasty and those with predeposited autologous blood were excluded on the grounds that patients in the revision group generally lost greater volumes of blood and that it would be unethical to restrict transfusion of the patients' own blood postoperatively.

A maximum allowable blood loss (MABL) was calculated for each patient based upon simple proportion using the formula of Kallos et al. ${ }^{12} \mathrm{MABL}=\mathrm{EBV} \times$ (Hctp - Hctmin)/Hctp, where EBV is the estimated blood volume, $70 \mathrm{ml} \cdot \mathrm{kg}^{-1}$, Hctp is the patient's preoperative Hct and Hct min was taken as 30 for men and 27 for women. The latter was chosen to avoid a tendency to overtransfuse women to a greater extent than men. ${ }^{13}$ Maintenance and deficit fluid replacement was with crystalloid. Blood loss up to the MABL was replaced with Haemaccel (polygeline colloid solution). Intraoperative blood loss was estimated by weighing swabs and measuring blood volume in suction bottles. Postoperative blood loss was estimated by the volume of blood in the suction drainage system (Redivac) up to the time of their removal which was usually $48 \mathrm{hr}$ postoperatively. When the MABL was reached, a Hct was performed and blood was given if the Hct was < Hctmin; otherwise replacement was with colloid. Het measurement was performed on the wards by nursing staff using a capillary technique and a semi-automatic haematocrit reader (Haematostat model C-70). Haemoglobin concentrations were measured at 24,48 and $72 \mathrm{hr}$ after operation and on the morning of discharge from hospital.

A discharge haematocrit exceeding $36 \%$ was chosen as the criterion to identify unnecessary transfusion. ${ }^{14,15}$ In an attempt to uncover any increased morbidity, which might be associated with these transfusion guidelines, all postoperative complications, duration of hospital stay 
TABLE III Mean transfusion in patients receiving blood, discharge haematocrit levels in overtransfused patients and duration of hospitalisation postoperatively

\begin{tabular}{|c|c|c|c|c|c|}
\hline \multicolumn{2}{|c|}{$\begin{array}{l}\text { Mean transfusion in patients receiving } \\
\text { blood }\end{array}$} & \multicolumn{2}{|c|}{$\begin{array}{l}\text { Discharge haematocrit levels in } \\
\text { overtransfused patients }\end{array}$} & \multicolumn{2}{|c|}{$\begin{array}{l}\text { Duration of hospitalisation } \\
\text { postoperatively }\end{array}$} \\
\hline $\begin{array}{l}\text { Number of } \\
\text { patients } \\
\text { transfiused }\end{array}$ & $\begin{array}{l}\text { Mean transfusion } \\
\text { (units) }\end{array}$ & $\begin{array}{l}\text { Number of } \\
\text { overtransfused } \\
\text { patients }\end{array}$ & $\begin{array}{l}\text { Mean } \\
\text { haematocrit (\%) }\end{array}$ & $\begin{array}{l}\text { Number of } \\
\text { patients }\end{array}$ & $\begin{array}{l}\text { Mean duration } \\
\text { of stay (Days) }\end{array}$ \\
\hline \multicolumn{6}{|l|}{ Control } \\
\hline 146 & $2.73 \pm 1.4$ & 66 & $39.3 \pm 2.5$ & 138 & $13.6 \pm 1.74$ \\
\hline \multicolumn{6}{|l|}{ Study } \\
\hline 26 & $1.31 \pm 0.46$ & 4 & $36.9 \pm 1.73$ & 77 & $13.1 \pm 1.69$ \\
\hline
\end{tabular}

after operation and a physiotherapy compliance assessment were recorded.

In order to assess the impact of the study on transfusion practice, we performed a retrospective comparison with data collected from the charts of 150 consecutive patients who fulfilled the study group criteria and had the same surgery performed before the introduction of the transfusion guidelines.

Student's $t$ test was used to assess statistical significance. A $P<0.05$ was considered to be statistically significant. Data are expressed as mean $\pm \mathrm{SD}$.

\section{Results}

Statistical analysis showed no differences between the control and study groups for men and women in age, weight, hip pathology, anaesthetic technique, preoperative haemoglobin/haematocrit concentrations or blood loss (Tables I, II).

Assessment of transfusion therapy showed that 146 (97\%) of patients in the control group were transfused a total of 398 units of blood with a mean of $2.6 \pm 1.4$ units (range 0-8 units). Four patients, all men, received no blood. The mean transfusion for women was $2.9 \pm$ 1.3 and for men $2.3 \pm 1.4$ units $(P<0.05)$.

Twenty-six (32\%) of the 80 patients in the study group were transfused a total of 34 units of blood with a mean of $0.42 \pm 0.67$ units (range $0-2$ units). For women, the mean transfusion was $0.52 \pm 0.69$ and for men $0.31 \pm$ 0.62 units $(P=\mathrm{NS})$. The amount of blood transfused was less in the study than in the control group, $1.31 \pm$ 0.46 vs $2.73 \pm 1.4$ units $(P<0.05)$ (Table III).

In the control group $58 \%$ of patients received blood in pairs of units without evaluating haemoglobin or haematocrit concentrations between units. In the study group no patient received blood in pairs unless the haemoglobin or haematocrit concentrations fulfilled the guideline requirements. In the control group at discharge, 68 patients had a haematocrit $>36 \%$ and two of these patients were not transfused. Excluding these two patients $45 \%$ of the control group patients were overtransfused. ${ }^{14,15}$ Of the study group, 12 patients had discharge haematocrit levels $>36 \%$. Eight of these 12 patients were not transfused, thus only four transfused patients had discharge haematocrits of $>36 \%$. This represents an overtransfusion rate of $5 \%$ in the study group (Table III).

There was no difference in the duration of postoperative inpatient stay between the two groups (Table III). In analysing this data any patients having thromboembolic complications were excluded on the basis that such a complication would significantly bias the overall duration of stay. There was no difference between the groups with reference to the incidence of postoperative complications.

Excluding patients with complications postoperatively whose physiotherapy programmes were modified, there was no difference between the groups in progress scoring.

\section{Discussion}

This study was established in order to review blood transfusion practice at our hospital and to introduce guidelines to eliminate overtransfusion practice. As the hospital is dedicated to elective orthopaedic surgery there is a homogenicity of practice in anaesthetic and surgical techniques and postoperative management. Although the study compared a prospective with a retrospective group, the two groups were comparable in relation to age, weight, anaesthetic technique, pathology, preoperative haemoglobin/haematocrit and total blood loss.

Most patients having total hip arthroplasty receive perioperative blood transfusion. ${ }^{10}$ The mean blood loss in the control group was $1440 \mathrm{ml}$ and $1462 \mathrm{ml}$ in the study group. These figures represent the middle of the range of blood for total hip arthroplasty reported by other groups. ${ }^{9,16}$ The overall transfusion rate in patients receiving blood loss was 2.7 units/patient and 1.31 units/patient in the control and study groups respectively compared with 3.4 units/patient (Friedman et al. (1979), ${ }^{17}$ and 2.5 units/patient (Sarma (1980)). ${ }^{18}$ It would 
appear that, compared with other groups, the blood loss and transfusion figures for the control group are middle of the range and probably, therefore, representative of blood loss and transfusion habits in many hospitals performing hip arthroplasty procedures.

Many variables influence the decision to commence blood transfusion including age, preoperative haemoglobin and haematocrit, and the presence of cardiovascular and respiratory disease. Most authors agree that a haematocrit of $30 \%$ or a haemoglobin of $10 \mathrm{~g} \cdot \mathrm{dl}^{-1}$ is safe and can be treated with oral iron therapy. ${ }^{19}$

The guidelines for transfusion in our group of patients were chosen following consideration of age and likely occult cardiorespiratory pathology. Other groups have demonstrated that much lower guidelines appear safe for patients free of cardiovascular disease. ${ }^{20}$ The mean values for the lowest haemoglobin concentrations for each patient throughout the study period, women $9.4 \pm 0.84$ (range 8.3-11.7), men $9.9 \pm 1.08$ (range 8.6-12.1) demonstrate that, at the extremes of the range, there is an $8 \%$ decrease below the transfusion trigger in women and $14 \%$ in the men. Determining a trigger value for transfusion must, therefore, take account of the likely decrease in haemoglobin concentration below this value in some patients.

Due to the age of our study population a discharge haematocrit of $36 \%$ was chosen as the determinant of overtransfusion. This resulted in $45 \%$ of cases being inappropriately transfused. These figures cannot be compared with those from other studies since quality assurance of transfusion practice for total hip arthroplasty has not been previously reported. However, in a study of patients undergoing a wide variety of surgical procedures, Giovenetti et al. (1988), ${ }^{14}$ using the same criteria, reported overtransfusion in 33\% of patients. Tartter and Barron $(1985)^{15}$ noted that $39 \%$ of patients undergoing surgery for colorectal cancer had been transfused unnecessarily. They used a discharge haematocrit of $>33 \%$ as indicating overtransfusion.

The introduction of our transfusion guidelines has led to a substantial reduction in the incidence of transfusion between the control and study groups ( $97 \%$ vs $32 \%$ ), together with a reduction in the amount of blood transfused to those patients receiving blood ( 2.73 units vs 1.31 units). In addition, there was a reduction in overtransfusion practice from $45 \%$ in the control group to $5 \%$ in the study group. It is important to stress that there was no difference in any measure of postoperative morbidity. It would appear that haemodilution to the guideline levels in this study was not associated with any increased risk for the patients in the study group.

As well as a reduction in the risks associated with transfusion, quality assurance programmes would also reduce the costs of transfusion therapy. Extrapolating our figures to an annual blood transfusion requirement for 300 total hip arthroplasty procedures per annum, the comparison would be 780 units per annum before the introduction of the transfusion guidelines, and 126 units since. This represents a saving of 654 units of blood per annum for total hip arthroplasties alone. In addition, were such guidelines employed for all surgical procedures, the overall reduction in transfusion requirements for a hospital would be substantial.

Having instructed the nursing staff on the wards in the use of the haematocrit machine, the conclusion was that the process was no more time-consuming than measuring blood glucose concentration with a glucometer: both take approximately three minutes.

In conclusion, the present study emphasizes the potential for reduction in blood transfusion in elective total hip replacement in our unit. This has implications in terms of patient safety and finance. Following this study, the nursing staff continue to use haematocrit machines on the wards and are now doing so in relation to total knee as well as hip arthroplasties.

\section{Acknowledgements}

We would like to thank Separation Technology Inc. for providing our haematocrit machines and the nursing staff at Cappagh Hospital for their cooperation throughout.

\section{References}

1 Myhre BA. Fatalities from blood transfusion. JAMA 1980; 224: 1333-5.

2 Haseltine WA. Silent HIV infections (editorial). N Engl J Med 1989; 320: 1487-9.

3 Gonzales J, Koch $M$. On the role of "transients" (biasing transitional effects) for the prognostic analysis of the AIDS epidemic. Am J Epidemiol 1987; 126: 985-1005.

4 Burrows $L$, Tarter $P$. Effect of blood transfusions on colonic malignancy recurrence rate (letter). Lancet 1982; 2: 662.

5 Blumberg N, Heal JM. Transfusion and host defenses against cancer recurrence and infection. Transfusion 1989; 29: 236-45.

6 Marsh J, Donnan PT, Hamer-Hodges DW. Association between transfusion with plasma and the recurrence of colorectal carcinoma. Br J Surg 1990; 77: 623-6.

7 Vogelsang $G B$. Transfusion-associated graft-versus-host disease in non-immunocompromised host. Transfusion 1990; 30: 101-3.

8 Anderson $K C$, Weinsten $H J$. Transfusion-associated graftversus-host disease. N Engl J Med 1990; 323: 315-21.

9 Woolson ST, Marsh JS, Tanner JB. Transfusion of previously deposited autologous blood for patients undergoing hip replacement surgery. J Bone Joint Surg (Am) 1987; 69A: $325-8$. 
10 Porteous MJ, Miller AJ. Blood transfusion in total hip replacement: is it always necessary? Ann R Coll Surg Engl 1991; 73: 44-5.

11 Cancilla $C$. JCAH to review clinical outcomes. American Medical News 1986; Sept. 19: 1-34.

12 Kallos T, Smith TC. Replacement for intraoperative blood loss. Anaesthesiology, 1974; 41: 293-5.

13 Friedman BA, Burns TL, Schork MA. An analysis of blood transfusion of surgical patients by sex: a quest for the transfusion trigger. Transfusion 1980; 20: 179-88.

14 Giovanetti AM, Parravicini A, Baroni L, et al. Quality assessment of transfusion practice in elective surgery. Transfusion 1988; 28: 166-9.

15 Tartter PI, Barron DM. Unnecessary blood transfusion in elective colorectal cancer surgery. Transfusion 1985; 25 : 113-5.

16 Thomson JD, Callaghan JJ, Savory CG, Stanton RP, Pierce $R N$. Prior deposition of autologous blood in elective orthopaedic surgery. J Bone Joint Surg (Am) 1987; 69A: 320-4.

17 Friedman $B A$. An analysis of surgical blood use in United States hospitals with application to the maximum surgical blood order schedule. Transfusion 1979; 19: 268-78.

18 Sarma DP. Use of blood in elective surgery. JAMA 1980; 243: $1536-8$.

19 Allen JB, Allen FB. The minimum acceptable level of hemoglobin. Int Anesthesiol Clin 1982; 20: 1-22.

20 Weisel RD, Charlesworth DC, Mickleborough LL, et al. Limitations of blood conservation. J Thorac Cardiovasc Surg 1984; 88: 26-38. 